education and children's age, night workers that intended to leave this work schedule showed greater chance of MPD $(\mathrm{OR}=2.14 ; 95 \% \mathrm{IC}: 1.09-4.23)$ when compared to those who did not express such a will.

Conclusions The time of exposure to night work does not seem to be relevant for the symptoms of mental health here studied. Analysing the intention to leave night work revealed to be an adequate approach to identify workers who are less tolerant to night work, thus possibly detecting those with higher chances of being affected as to their mental health.

\section{CANCER MORTALITY IN THE BRITISH RUBBER INDUSTRY - A 45 YEAR FOLLOW-UP}

${ }^{1}$ Damien McElvenny, ${ }^{2}$ Raymond Agius, ${ }^{1} J o h n$ Cherrie, ${ }^{2}$ Frank de Vocht. ${ }^{1}$ IOM, Edinburgh, UK; ${ }^{2}$ The University of Manchester, Manchester, UK

\subsection{6/oemed-2014-102362.273}

Objectives Working in the rubber and rubber product manufacturing industry has been classified by the International Agency for Research on Cancer (IARC) as definitely carcinogenic. However, given the complex nature of the chemicals, the phasing out of the use of certain chemicals, and the trend in reduction in exposures, there remains a great deal of uncertainty about the nature of the risks, if any, encountered by workers today.

Method We have at our disposal a large retrospective cohort study of $40000+$ workers who were aged $35+$ in 1967, which was last followed up to 1976 . We are carrying out an updated cancer mortality analysis adding 35 years to the previous cancer mortality follow-up. We will determine the nature of the doseresponse relationships for important known and suspected carcinogens using quantitative exposure modelling based on available measurement data from the EXASRUB project (dust, fumes, solvents, and n-Nitrosamines).

Results We will report on progress to date with the study, which has received ethical approval and is currently seeking other clearances from the UK research governance system for such studies, and will further report on proposed exposure modelling strategies.

Conclusions This is the largest and statistically most powerful cohort of its type and will have an exhaustive, quantitative exposure assessment. This study will add substantially to our knowledge of the longterm risks associated with the chemicals present in the industry in the UK, including those from working conditions several decades ago, and will thereby also be important for exposure conditions in the developing world.

\section{THE ASSOCIATION BETWEEN SHIFT WORK AND OBESITY IN CANADA: A CROSS-SECTIONAL STUDY USING A NOVEL EXPOSURE ASSESSMENT TOOL}

\footnotetext{
1,2Victoria Kirsh, ${ }^{1,2}$ Michelle Cotterchio, ${ }^{1}$ Natalie McGlynn. ${ }^{1}$ Cancer Care Ontario, Toronto,
} Ontario, Canada; ${ }^{2}$ University of Toronto, Toronto, Ontario, Canada

\subsection{6/oemed-2014-102362.274}

Objectives Shift work entailing circadian rhythm disruption is linked to chronic disease. One suggestion is that obesity mediates the relationship, yet research investigating the link between shift work and obesity report mixed findings, with a propensity towards a positive association. Since a paucity of research in this area has been conducted in Canada, this study examined the association between shift work and obesity within two Canadian studies; one of Ontario females, and the other, a highly educated nation-wide sample.

Method Healthy subjects from the Canadian Study of Diet, Lifestyle, and Health cohort study (CSDLH; 1447 males, 2170 females), and the Ontario Women's Diet and Health case-control study (OWDHS; 3474 female controls) were analyzed. Overweight was defined as $\mathrm{BMI} \geq 25,<30$, and obesity: $\mathrm{BMI} \geq 30$.

Reported occupation was linked to shift work exposure assessment, defined as regular evenings, nights, or rotating work, derived from Survey of Labour and Income Dynamic data. The association between shift work (tertiles), and obesity, separated by sex and dataset, was determined through polytomous and logistic regression controlling for potential confounders.

Results In adjusted regression (reference=lowest exposure), intermediate shift work was negatively associated with overweight for CSDLH females (OR: 0.51, 95\% CI: 0.26-0.99), yet positively associated with obesity for OWDHS females (OR: 1.71, 95\% CI: 1.08-2.71). For males, high shift work exposure was negatively associated with increased weight (OR: 0.57, 95\% CI: $0.35-0.92$ ).

Conclusions The association between shift work and obesity is multifaceted and depends on population factors. Further investigations within a highly educated and diversified workforce are warranted.

\section{MUSCULOSKELETAL DISORDERS (MSDS) AND WORKING RISK FACTORS}

${ }^{1}$ Milan Tucek, ${ }^{2}$ Jana Hlavkova. ${ }^{1}$ First Faculty of Medicine, Institute of Hygiene and Epidemiology, Charles University, Prague, Czech Republic; ${ }^{2}$ National Institute of Public Health, Prague, Czech Republic

\subsection{6/oemed-2014-102362.275}

Objectives In the Czech Republic the musculoskeletal disorders (MSDs) represent a major problem. Their frequency has been continually increasing to the degree that they currently rank as the second most frequent cause of temporary working disability. The MSDs represent 50\% (607 cases) of the officially recognised occupational diseases (incidence 30.3/100 000 employees) and are the most frequent category of occupational diseases in the Czech Republic.

Method The authors describe the Czech Republic official national system of hazard identification and risk/exposure assessment ("Categorization of working operations") used as a basic tool for effective risk management in enterprises (database of 74 731 subjects/enterprises in 2011) and analyse 4353 occupational MSDs during 2005-2011.

Results Working population in the Czech Republic currently totals about 4.5 million people. Of them, about 117 thousand are exposed to vibrations (» $2.6 \%$ of total work force), about 739 thousand are exposed to overload by physical work (»16\% of total work force), and about 600 thousand are working in a bad working posture (» $13 \%$ of total work force). It follows that almost $30 \%$ of the Czech total work force is exposed to a risk factor for MDSs.

Conclusions The goal of the system of categorization of working operations is to get objective and comparable data for risk assessment, optimisation of working conditions, rational measures and handling problems. Authors emphasise consultative role of occupational health services (OHSs) in the hazard identification and risk/exposure assessment.

Supported by scientific programme PRVOUK P25/LF1/2 of Charles University in Prague, Czech Republic. 